\title{
Complex and prolonged skin toxicity after superficial brachytherapy for basal cell carcinoma on the lower leg
}

\author{
Agata Rembielak, BSc, MD, PhD \\ The Christie NHS Foundation Trust and The University of Manchester, Manchester, UK
}

\begin{abstract}
Superficial brachytherapy (BT) is used to treat skin cancers at various locations. In areas of poor vascularization, which are subjected to constant trauma, such as extremities, radiotherapy may cause prolonged healing, poorly treatable chronic ulcerations, and even necrosis, requiring subsequent surgical intervention. In this case study, we report on an elderly patient with basal cell carcinoma located on lower leg that was treated with superficial BT. The cancer was cured, but the patient developed complex and prolonged skin toxicity that eventually resolved after 15 months.

J Contemp Brachytherapy 2020; 12, 4: 406-411 DOI: https://doi.org/10.5114/jcb.2020.98121
\end{abstract}

Key words: BCC, superficial brachytherapy, toxicity, leg ulcer.

\section{Case report}

An eighty-four-year-old woman presented to The Christie Hospital, Manchester, UK, with a 4-month history of a non-healing ulceration affecting her right anterior shin. The lesion bled occasionally, and the patient commented on the lesion catching on her clothes. Skin punch biopsy from the lesion confirmed basal cell carcinoma with mixed reticulate and infiltrative pattern, with no evidence of an atypical squamous component and no lymphovascular or perineural invasion.

On clinical examination, the lesion measured $1.6 \mathrm{~cm}$ $\times 1.3 \mathrm{~cm}$ and was approximately $2.56 \mathrm{~mm}$ thick as per high frequency skin ultrasound. The lesion did not tether underlying tissues and there was no palpable regional lymphadenopathy present. Skin condition and vascularization on the lower legs were assessed as adequate for the patient's age, with no evidence of major atrophy or significant vascular insufficiency. The patient was otherwise fine and fit for her age. Her past medical history included gastric MALToma, left hemicolectomy for Dukes $\mathrm{B}$ sigmoid carcinoma, and hypertension.

She was reviewed by her surgical team and declined excision having a background of varicose veins in the past. After detailed discussion with the patient regarding possible treatment options, she agreed for superficial high-dose-rate (HDR) brachytherapy (BT) and was referred to the Brachytherapy Department at the Christie.

The patient provided written consent to take medical illustration and agreed for publishing her case report, including photographs. The patient specifically agreed for the case to be used for educational purposes. Rationale and logistics for skin BT, together with possible acute and chronic side effects from treatment were discussed in detail and the patient provided written permission for skin BT. Due to lower leg location, during consent, the patient was particularly informed of increased risk of long-term toxicity with possible non-healing skin ulceration in BT site, requiring long-term dressings and/or surgical involvement. In line with The Christie guidelines, she was also advised on skin care during and after BT, and provided with written information on skin radiotherapy, including skin care leaflet [1,2]. In the skin care advice, patients are encouraged to use any moisturizing cream as per patient wish, providing that it does not cause any contact allergy. Skin moisturizing cream should be applied during and after radiotherapy.

\section{Brachytherapy technique}

The patient was treated with superficial HDR-BT with mould. The mould was $9 \mathrm{~mm}$ thick and composed of $4 \mathrm{~mm}$ bolus and $5 \mathrm{~mm}$ flap as per Christie skin BT method (Figure 1). Three-dimensional computed tomography (CT)-based planning was done using CT slices $2 \mathrm{~mm}$ thick reconstructed at $1 \mathrm{~mm}$ using CT Big Bore (Philips Medical Systems B.V., The Netherlands). To ensure proper visualization, metallic markers were placed at the edge of the tumor area and in the tubes. During the planning scan, the proper positioning of the mould with flap was verified in order to avoid any misplacement or air gaps. 


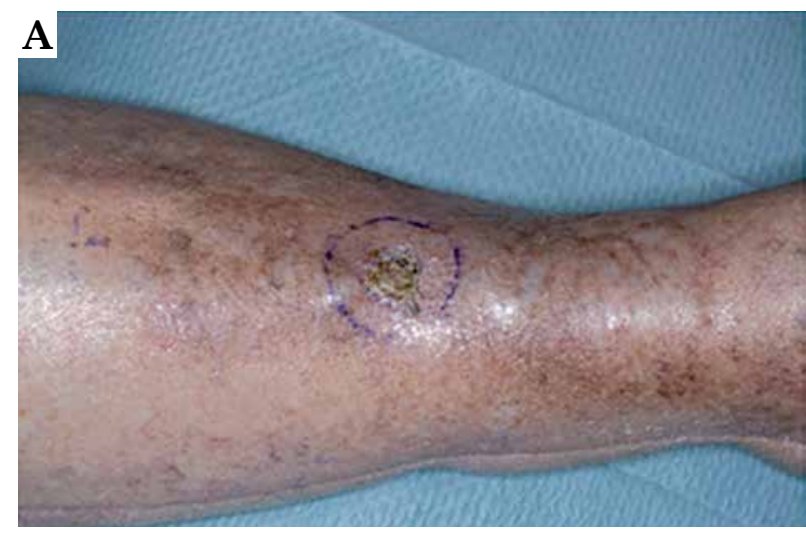

Fig. 1. BCC skin anterior shin - skin mark out and mould

Planning was done using Oncentra Brachytherapy version 4.5.2 (Elekta Instrument AB Stockholm, Sweden). Evaluation of the plan was performed using slice by slice visualization. The technique at the time of this treatment was to prescribe to the skin surface and cover the treatment volume with the $80 \%$ isodose line. Currently, the Christie protocol prescribes skin BT to $100 \%$ isodose in line with other BT centers. The dose was prescribed at $3 \mathrm{~mm}$ depth.

The patient received HDR-BT with a superficial mould. Due to the location of the lesion on the lower leg, the Christie standard prescribed dose of $40 \mathrm{~Gy}$ to $80 \%$ isodose (equivalent of 32 Gy to $100 \%$ isodose) was reduced in this case to $37.50 \mathrm{~Gy}$ to $80 \%$ (equivalent of $30 \mathrm{~Gy}$ to $100 \%$ ). Further details of the Christie technique at the time of this treatment are included in Table 1 . The dose was delivered in eight fractions, twice a day, with a minimum sixhour break between fractions over four consecutive days. The prescribed BT course was delivered without any

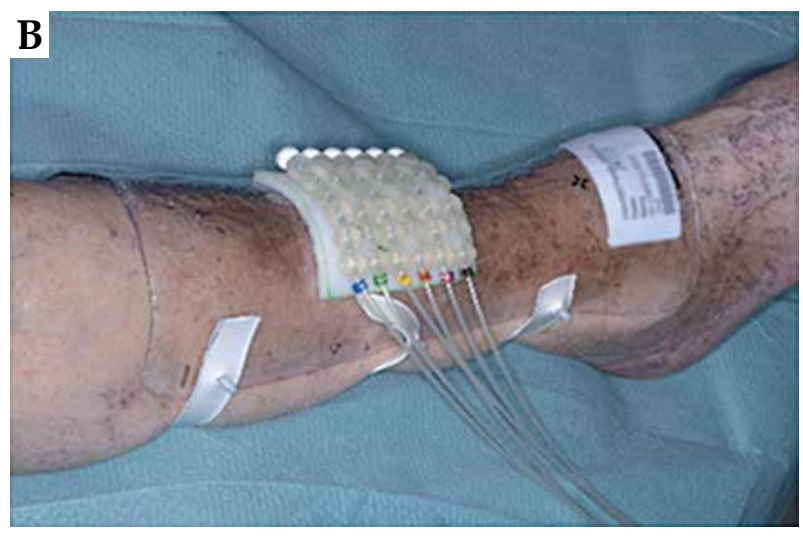

problems and the patient was fully compliant. HDR-BT plan parameters are presented in Figure 2.

\section{Follow-up}

No skin reaction was noted by the treating team during or immediately after BT. Six weeks after the completion of BT, around the time of routine post-BT follow-up appointment, the general practitioner (GP) contacted the treating team to inform that the patient had developed a skin infection within the radiotherapy area and was prescribed flucloxacillin empirically $500 \mathrm{mg}$ q.d.s. She was reviewed at the Christie at the end of her 2-week course of antibiotic. At that time, her anterior shin wound in the BT site appeared weepy with very fragile surrounding skin. The patient was very symptomatic from her wound and any intervention over it caused significant pain. Her wound was cleaned with saline and non-adhesive dressing (Mepilex ${ }^{\circledR}$ ) was placed. No further

Table 1. Treatment plan parameters for skin HDR brachytherapy

\begin{tabular}{|c|c|}
\hline Treatment details & HDR contact brachytherapy to skin BCC on the right shin \\
\hline BT prescription & $\begin{array}{l}37.5 \text { Gy to the skin surface in } 8 \text { fractions, } 4.69 \text { Gy per fraction* } \\
\text { *The technique at the time of this treatment was to prescribe to the skin surface and cover } \\
\text { the treatment volume with the } 80 \% \text { isodose line } \\
\text { The dose planned to cover the treatment volume is } 80 \% \text { of } 37.5 \text { Gy }=30 \text { Gy; } 30 \text { Gy total dose } \\
\text { in } 3.75 \text { Gy per fraction }\end{array}$ \\
\hline Target definition & $\begin{array}{c}\text { GTV }=\text { CTV } \\
\text { CTV }+0.5 \mathrm{~cm}=\text { PTV } \\
\text { PTV volume } 2.85 \mathrm{cc} \\
\text { Prescription depth at } 3 \mathrm{~mm}\end{array}$ \\
\hline Number of active catheters used & 4 \\
\hline Optimization method & Graphical \\
\hline Treatment plan parameters & $\begin{aligned} D_{90} & =3.69 \mathrm{~Gy} \\
\mathrm{~V}_{100} & =0.26 \mathrm{~cm}^{3} \\
\mathrm{D}_{95} & =3.59 \mathrm{~Gy} \\
\mathrm{~V}_{95} & =0.71 \mathrm{~cm}^{3}\end{aligned}$ \\
\hline Maximum skin dose & $\begin{array}{l}\text { Maximum skin dose is } 110 \% \text { and located in the center of the lesion, not at the healthy skin. } \\
\text { Maximum skin dose in small area of healthy skin around the lesion does not exceed } 95 \%\end{array}$ \\
\hline $\mathrm{BED}$ and $\mathrm{EQD}_{2}$ & $\begin{array}{l}\text { BED for } 100 \%=55.1 \mathrm{~Gy} \text {, for } 80 \%=41.25 \mathrm{~Gy} \\
\mathrm{EQD}_{2} \text { for } 100 \%=45.9 \mathrm{~Gy} \text {, for } 80 \%=34.4 \mathrm{~Gy} \\
\text { The above are calculated using } \alpha / \beta \text { ratio of } 10\end{array}$ \\
\hline
\end{tabular}



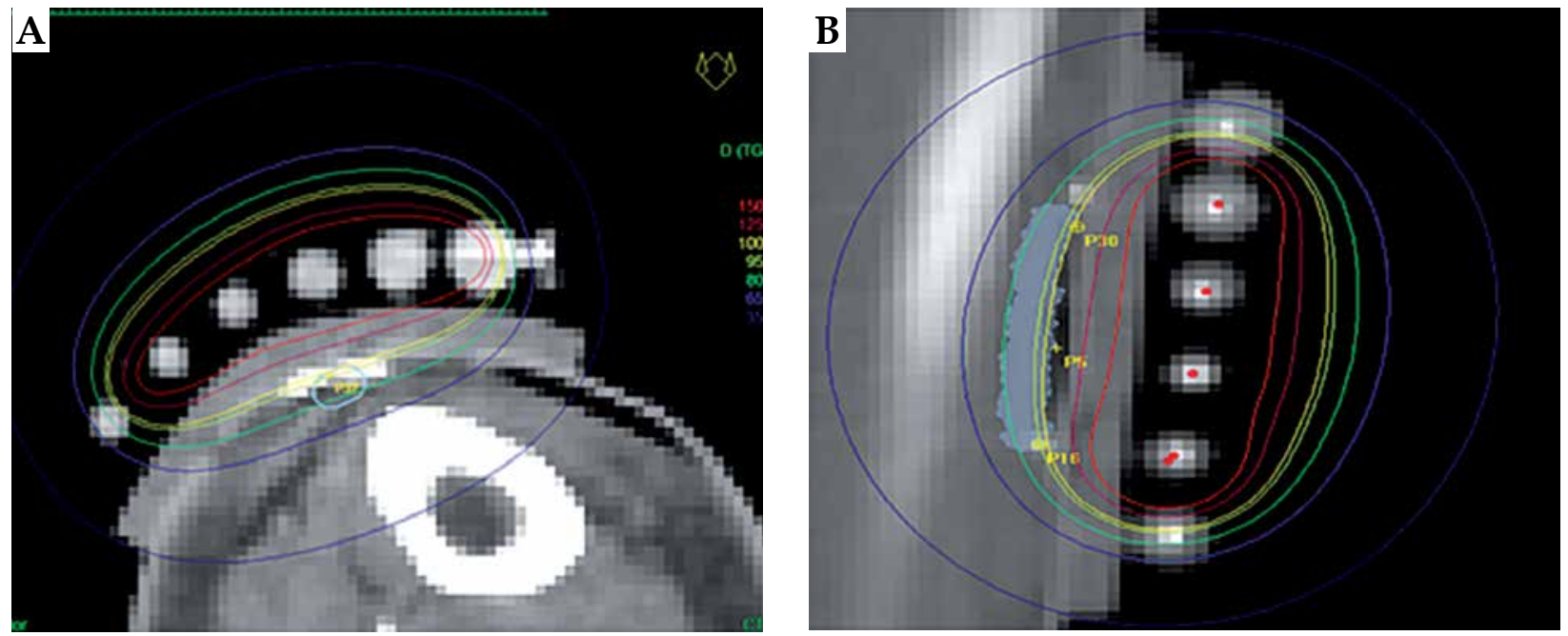

Fig. 2. Isodose distributions in BT plan that was used to treat the patient

antibiotic was felt necessary at this stage. She was also prescribed oral painkillers (paracetamol $1 \mathrm{~g}$ and codeine $30 \mathrm{mg}$, both p.r.n. and maximally q.d.s.). The patient was also referred to the community dressing team for further management, which could be provided more locally for the patient.

Three days after the hospital appointment, the community district nurse contacted the treating team concerned about the wound appearance, mainly black in color with odorous discharge. The patient was reviewed in the next three days at the Christie. The clinical examination revealed a large odorous wound measuring $6 \mathrm{~cm} \times 4 \mathrm{~cm}$ with visible central necrotic masses. Wound swab confirmed significant growth of anaerobes and she was prescribed oral metronidazole $400 \mathrm{mg}$ t.i.d. for 7 days. Her wound was cleaned and a non-adhesive dressing $\left(\right.$ Mepilex $\left.^{\circledR}\right)$ was applied. The patient continued paracetamol and codeine and reported improved analgesia. Follow-up visit after 7 days showed the lesion had improved in appearance with no odor present. At this stage, the hospital tissue viability nurse (TVN) was asked to review the patient and to advise on further management. In addition to regular wound cleaning, TVN added a desloughing wound algorithm to the patient's management and suggested hydrogel. TVN also added consideration of compression bandaging following Doppler examination, providing that the oncologists did not have any concerns regarding local cancer progression. From that point, the patient attended the Christie every two to four weeks, pending clinical need. Each time, the patient was reviewed jointly by an oncologist and TVN. This close follow-up continued for the next 10 months. These appointments were organized in addition to twice a week involvement from the local community dressing team. At 5 months after the completion of BT, Coloplast ${ }^{\circledR}$ dressing was added to Mepilex ${ }^{\circledR}$ and at 6 months, UrgoClean ${ }^{\circledR}$ dressing was advised to help further with the debridement and desloughing phase of chronic wound inflammation. At the same time, she was referred to the community ulcer clinic where, after uneventful Doppler examination of the right lower leg, the patient was advised on compression stockings.

The case was also discussed with plastic surgeons and had joint review at 5 months after the completion of BT regarding possible residuum or early recurrence and to consider skin biopsy. Plastic surgeons did not feel that the picture was consistent with clinical recurrence and did not advise on skin biopsy due to very fragile skin. Plain X-ray of right tibia and fibula did not show any evidence of bone necrosis or infection at this stage. The patient continued under very close clinical follow-up with her oncology and TVN team and attended regular dressing appointments with the community dressing and ulcer clinic. Her wound eventually healed completely when reviewed 15 months after the completion of BT. Medical illustrations taken at BT planning and at follow-up are shown in Figure 3. After 2 years from the BT completion, the patient was eventually discharged back to her GP's care being asymptomatic from her right anterior shin area, with no evidence of local or regional recurrence. Her wound has remained completely healed. Detailed time scale of events is presented in Figure 4.

\section{Discussion}

Skin lesions located on the lower legs present a significant clinical challenge. Current treatment recommendations are in favor of surgical management. Other methods of treatment involve radiotherapy [3], electrodessication, curettage, cryotherapy, and photodynamic therapy. Some guidelines do not even recommend radiotherapy in limb locations and suggest avoidance particularly in the elderly population due to risk of osteonecrosis [4,5].

In radiotherapy settings, BT offers a more favorable dose distribution to external beam radiotherapy due to rapid dose fall off and ability to spare fragile normal tissues.

Areas of poor vascularization, such as lower limbs, are subjected to constant trauma. In such locations, radiotherapy may lead to prolonged healing, radiother- 

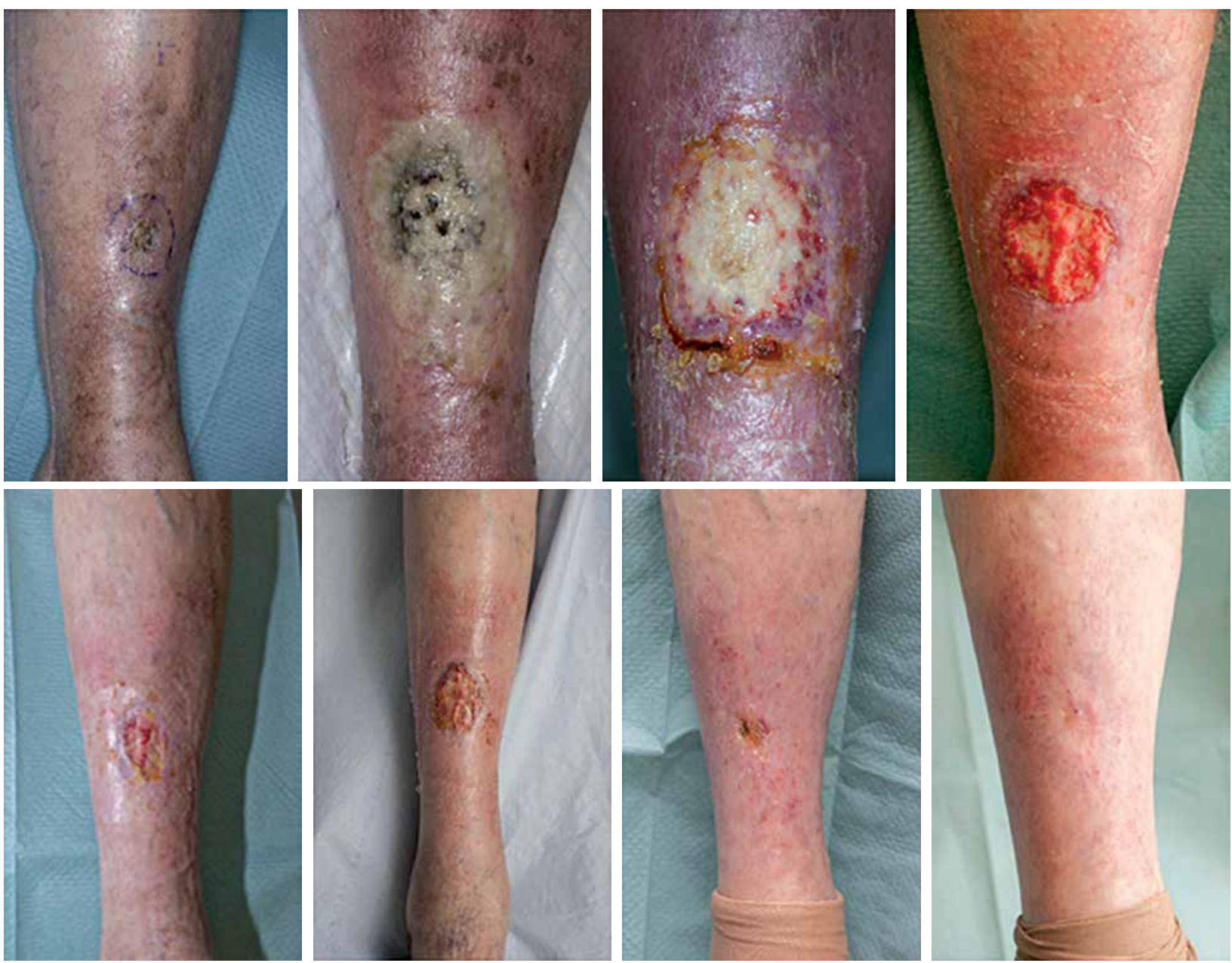

Fig. 3. Skin appearance at mark out, and then at 2, 4, 6, 8, 11, 13, and 15 months after completion of skin superficial BT

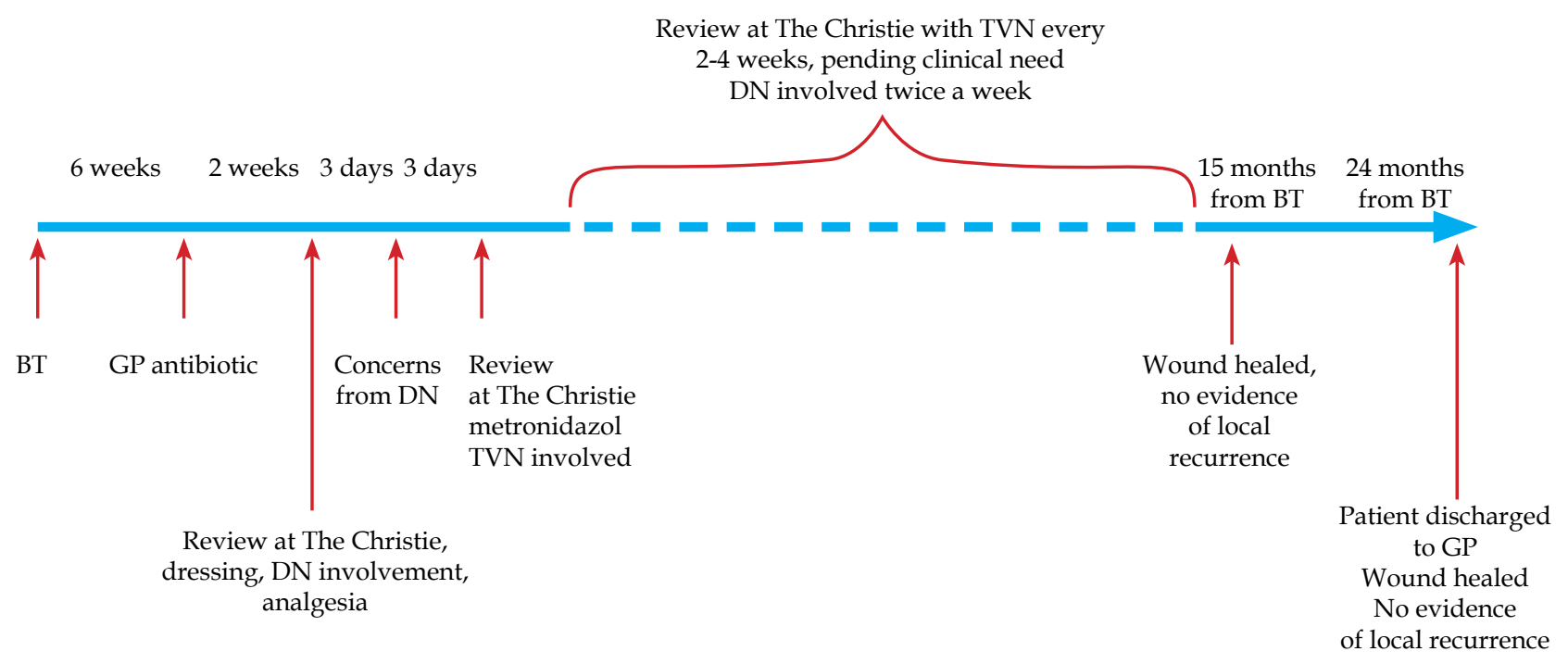

$T V N$ - tissue viability nurse $D N$ - district nurse $G P$ - general practitioner

Fig. 4. Detailed time scale of events 
apy-related ulcerations, and even necrosis, requiring surgical input. With external beam radiotherapy, particularly X-ray treatment, some authors also raise concerns regarding risk of osteonecrosis or chondronecrosis. Such risks have been particularly of concern in lesions over the anterior tibia or hand, or in ear locations, where radiation-related damaged could lead to a damage of tendons, joints, and bones, with resultant impaired hand function [6]. However, many of the patients with non-melanoma skin cancer (NMSC) on extremities are elderly and frail and/or with co-morbidities precluding surgery. In some cases, surgery requires amputation, which can be life-debilitating for the patients. Therefore, a non-invasive treatment options may be preferred. Among radiation types used in treatment of skin cancer, electron beams are common, but they prove dosimetrically challenging and are often not suitable in lesions located on curved surfaces or small skin cancers. Radiotherapy, using a BT technique, is a well-established option in such cases. In $\mathrm{BT}$, the radioactive source is placed in direct proximity of the target volume, with normal tissues outside the target volume receiving a negligible radiation dose. Computer treatment planning process maximizes the dose to the target volume while minimizing unwanted dose delivery to organs at risk, such as bone or tendon. This process ensures increased chances of cure and reduced risk of late radiation-related toxicity. Therefore, it is regarded that BT offers viable radiation option in lesions over bones or cartilage, where traditional external beam radiotherapy (electrons) may be less safe [7].

In the literature, there is limited number of publications regarding the use of BT in NMSC in limb locations. Usually, literature reports gather various skin cancer locations with extremities among the others, and available outcomes are analyzed and reported together for all sites. Therefore, it is almost impossible to draw any conclusion on efficacy and toxicity of NMSC treated on extremities out of such publications. One of the biggest reported series of skin BT (radon mould technique) in NMSC comes from the Peter MacCallum Cancer Centre [8]. It included 642 patients with lesions located in upper limbs in $49 \%$ of cases and lower limbs in $17 \%$. Gauden et al. reported on a series of 200 patients with 236 lesions treated, of which, 26 were located on extremities [9]. The treatment was delivered by HDR-BT, with Leipzig-type applicator. Total dose of $36 \mathrm{~Gy}$, in $3 \mathrm{~Gy}$ per fraction, given daily over 2 weeks was prescribed to between 3 to $4 \mathrm{~mm}$. Local control was achieved in $98 \%$ of cases. Grade 1 acute skin toxicity was reported in 168 treated lesions (71\%) and grade 2 , in $81(34 \%)$. Cosmesis was assessed as good or excellent in 208 cases $(88 \%)$. Late skin hypopigmentation was noted in 13 cases (5.5\%). Four patients recurred locally and underwent subsequent surgery.

Svoboda et al. published a series of 137 skin lesions of various pathologies (primary skin cancers and metastases to skin from other origins) treated in 87 patients with HDR-BT. Total dose ranged from 12-50 Gy, given in 1-15 fractions prescribed at the surface of applicator. Out of 137 lesions treated, 16 lesions were located on the hands, 5 on the arms, and 13 on the lower extremities. Full re- sponse was obtained in all but four basal cell carcinomas (BCCs). The authors did not report any severe acute or late toxicity [10].

Joslin and colleagues elaborated on 20 cases treated with $45-47.5$ Gy in 10 or 11 fractions [11]. Poor healing affected 3 cases, with superficial necrosis involving 3 other cases (one following injury). The authors concluded that careful consideration of dose fractionation regimes is required in lower extremities.

Many of the published articles in the field are relatively old, some presenting older techniques in radiotherapy and BT pre-computer planning. This transpires also in the references section below. Unfortunately, the information on significant radiation toxicity because of BT persists among our non-BT colleagues. It is ultimately up to us to increase our BT presence and show the wider audience not only what we do well, but also what we have learned from past experience, and how BT has improved in terms of efficacy and safety for our patients and staff. There is however a recently observed increased number of publications on the benefits of skin BT, including leg location $[12,13,14,15]$. Some of these publications specifically focus on the benefit of BT in the elderly population $[16,17]$. We sincerely hope that our readers would further contribute to this trend.

\section{Issues suggested for Readers' consideration (not exhaustive)}

In order to start discussion, we have suggested a few questions to our Readers:

1. Would you offer BT in this case/location or maybe external beam radiotherapy instead? If so, why?

2. Is fractionation adequate or should this be altered, e.g., to daily. If so, what is your proposed fractionation schedule in this case?

3. Could the immediate post-BT infection be a contributing factor in radiation-related toxicities?

4. When should we consider skin biopsy in such complex cases?

5. Any comments or suggestions on wound management?

6. Would this experience change how you counsel a patient with skin BT on leg location?

\section{Suggested further reading}

1. Shack RB. Management of radiation ulcers. South Med J 1982; 75: 1462-1466.

2. Bin Mh Busra MF, Chowdhury SR, Bin Ismail $F$ et al. Tissue - engineered skin substitute enhances wound healing after radiation therapy. Adv Skin Wound Care 2016; 29: 120-129.

3. Podd TJ. Treatment of lower limb basal cell and squamous cell carcinomas with radiotherapy. Clin Oncol (R Coll Radiol) 1992; 4: 44-45.

4. Cox NH, Dyson P. Wound healing on the lower leg after radiotherapy or cryotherapy of Bowen's disease and other malignant skin lesions. Br J Dermatol 1995; 133: 60-65. 


\section{Acknowledgements}

We would like to thank brachytherapy and medical physics teams at the Christie, particularly Lisa Hallett, for their help in preparation of BT planning data.

\section{Disclosure}

The author reports no conflict of interest.

\section{References}

1. Radiotherapy to the skin. A guide for patients and their carers. The Christie. https://www.christie.nhs.uk/media/ 2341/401.pdf

2. Skin care during and after your radiotherapy treatment. The Christie. https://www.christie.nhs.uk/media/6438/145.pdf

3. Szabó P. Radiotherapy of carcinomas of the dorsum manus. Strahlentherapie 1981; 157: 242-244.

4. London Cancer. Skin Cancer Radiotherapy Guidelines. August 2013. http://londoncancer.org/media/76382/london-cancer-skin-radiotherapy-guidelines-2013-v1.0.pdf

5. Royal College of Radiologists UK. Radiotherapy dose fractionation $3^{\text {rd }}$ edition. March 2019. https://www.rcr.ac.uk/system/files/publication/field_publication_files/bfco193_radiotherapy_dose_fractionation_third-edition-skin-cancer_0.pdf

6. Allan E, Stanton A, Pye, D et al. Fractionated high dose rate brachytherapy moulds - a precise treatment for carcinoma of the pinna. Radiother Oncol 1998; 48: 277-281.

7. Alam M, Nanda S, Mittal BB, et al. The use of brachytherapy in the treatment of nonmelanoma skin cancer: a review. See comment in PubMed Commons belowJ Am Acad Dermatol 2011; 65: 377-388.

8. Ainslie J, Ashby MA, Pacella JA et al. Use of radon mould technique for skin cancer: results from the Peter MacCallum Cancer Institute (1975-1984). Br J Radiol 1989; 62: 608-612.

9. Gauden R, Pracy M, Avery AM et al. HDR brachytherapy for superficial non-melanoma skin cancers. J Med Imaging Radiat Oncol 2013; 57: 212-217.

10. Svoboda VH, Kovarik J, Morris F. High dose-rate microselectron molds in the treatment of skin tumors. Int J Radiat Oncol Biol Phys 1995; 31: 967-972.

11. Joslin CA, Flynn A, Hall EJ. Principles and practice of brachytherapy using afterloading systems. Chapter 29. Arnold Publishers 2001; p. 389.

12. Guinot JL, Rembielak A, Perez-Calatayud J et al. GECESTRO ACROP recommendations in skin brachytherapy. Radiother Oncol 2018; 126: 377-385.

13. High dose rate brachytherapy in elderly patients with non-melanoma skin cancer - clinical and cosmetic outcome. RSNA press. http://press.rsna.org/pressrelease/2019_resources/2135/abstract.pdf

14. Keen CE. HDR brachytherapy effective for elderly patients with nonmelanoma skin cancers. Applied Rad Oncol. https:/ / appliedradiationoncology.com/articles/hdr-brachytherapy-effective-for-elderly-patients-with-common-skin-cancers

15. Likhacheva A, Awan M, Barker CA et al. Definitive and postoperative radiation therapy for basal and squamous cell cancers of the skin: Executive summary of an American Society for Radiation Oncology Clinical Practice Guideline. Pract Radiat Oncol 2020; 10: 8-20.

16. Lancellotta V, Kovács G, Tagliaferri L et al. The role of personalized interventional radiotherapy (brachytherapy) in the management of older patients with non-melanoma skin cancer. J Geriatr Oncol 2019; 10: 514-517.

17. Lancellotta V, Kovács G, Tagliaferri L et al. Age is not a limiting factor in interventional radiotherapy (brachytherapy) for patients with localized cancer. Biomed Res Int 2018: 2178469. doi: $10.1155 / 2018 / 2178469$. 